Journal of Advanced Research in Fluid Mechanics and Thermal Sciences

Journal homepage: www.akademiabaru.com/arfmts.html ISSN: 2289-7879

\title{
Effects of Viscous Dissipation on Mixed Convection Boundary Layer Flow Past a Vertical Moving Plate in a Nanofluid
}

\author{
Muhammad Khairul Anuar Mohamed ${ }^{1, *}$, Mohd Zuki Salleh ${ }^{2}$, Anuar Ishak ${ }^{3}$ \\ Faculty of Engineering Technology, DRB-HICOM University of Automotive Malaysia, Peramu Jaya Industrial Area, 26607 Pekan, Pahang, \\ Malaysia \\ 2 Centre of Mathematical Sciences, Universiti Malaysia Pahang, 26300 Kuantan, Pahang, Malaysia \\ 3 School of Mathematical Sciences, Faculty of Science and Technology, Universiti Kebangsaan Malaysia, 43600 UKM Bangi, Selangor, Malaysia
}

\section{ARTICLE INFO}

\section{Article history:}

Received 22 October 2019

Received in revised form 4 December 2019

Accepted 5 December 2019

Available online 13 April 2020

\section{ABSTRACT}

Adaptation from the thermal management applied in modern engine cooling system and central processing unit (CPU) in performance computer devices, present study solved the problem of steady mixed convection boundary layer flow and heat transfer on a moving vertical plate in a nanofluid with the presence of viscous dissipation and constant wall temperature. The mathematical model which is in non-linear partial differential equations is solved numerically by similarity transformation approach with the Keller-box method. The characteristics and effects of pertinent parameters considered which are Prandtl number, Lewis number, Eckert number, Brownian motion parameter, thermophoresis parameter, mixed convection parameter, concentration mixed convection parameter and plate velocity parameter are analyzed and discussed. In conclusion, there exist dual solutions in opposing flow for moving parameter range $0.18<\varepsilon<0.48$. Further, the increase of mixed convection parameter in assisting flow results to the increase in the Nusselt number and skin friction coefficient.

Keywords:

Heat transfer; mixed convection; moving

vertical plate; nanofluid; viscous

dissipation

Copyright @ 2020 PENERBIT AKADEMIA BARU - All rights reserved

\section{Introduction}

A study on the boundary layer flow regarding the constant speed moving plate was first studied by Sakiadis [1]. Known as Sakiadis flow, this boundary layer flow is quite different from Blasius flow past a flat plate. Erickson et al., [2] expanded the research scope by considering the effect of suction and injection on the flow. Further, the study regarding this topic has been extended with the presence of other physical effects including magnetic field, thermal radiation, porous effect, variable wall temperature, Ohmic heating, slip and convective boundary conditions by Damseh et al., [3],

\footnotetext{
* Corresponding author.

E-mail address: khairul.anuar@dhu.edu.my (Muhammad Khairul Anuar Mohamed)
} 
Ishak et al., [4], Jahan et al., [5], Mutlag et al., [6], Chamkha et al., [7] and recently by the works of Jamaludin and Nazar [8], Anuar et al., [9] and Shamshuddin et al., [10].

Growth in nanotechnology has encouraged the researchers to investigate the boundary layer flow in a nanofluid. Latest study consider the boundary layer flow in a nanofluid include the investigations by Zeeshan et al., [11], Hayat et al., [12] and Jusoh et al., [13] who considered the magnetohydrodynamic flow, activation energy in Couette-Poiseuille flow and melting heat transfer of nanofluids past a bidirectional exponential permeable stretching/shrinking sheet with viscous dissipation, chemical reaction and convective boundary conditions. It is concluded that the velocity distributions show an increasing behavior for larger nanomaterial volume fraction. Further, it is perceived that the velocity of nanofluid decelerate by increasing the values of the modified magnetic parameter, whereas the temperature and concentration profile is increased by increasing the said parameters. Other related study on nanofluid included the works by Muhammad et al., [14,15], Barnoon et al., [16], Toghraie et al., [17], Ishak et al., [18] and Alkasasbeh et al., [19]

The combinations of boundary layer flow on a flat plate and a nanofluid has been applied widely in order to solve the thermal management problems. For example, it is applied in most water cooler automotive engine system and central processing unit (CPU) in performance computer devices. The nanosize of particles in nanofluid gives minimum kinetic energy in collisions onto a component surface such as the water pump, pipelines and bearings. Thus, nanofluid is expected to gives little friction or no damage on component surfaces and hence enhanced the component lifetime [20,21]. $\mathrm{Hu}$ and Dong [22] suggested that nanoparticles like titanium oxide in oil reduced the skin friction coefficient, which improved the lubricating properties.

According to Wang and O. D. Leon [23], the enhancement in nanofluid thermal conductivity has allowed the aerodynamic vehicle's design which contributed to energy efficiency. By employing the nanofluid as coolant, the small size of radiator is sufficient to cooling down the engine. The small size radiator design in front of the vehicle may reduce the drag coefficient thus minimize the air resistant towards vehicles, which results in the improvement in fuel consumption.

Usually, in modelling boundary layer flow and heat transfer, the viscous dissipation effect is neglected in the energy equation [24]. This is due to the assumption that the viscous dissipation effect is small in fluid flow. This assumption might be true for some cases but it is unproven to valid in any problems. Further, there is a little study has been done to support this assumption.

Therefore, the present study considered the mixed convection boundary layer flow on a moving vertical plate in a nanofluid with a viscous dissipation effect. Viscous dissipation or internal friction is the rate of the work done against viscous forces that are irreversibly converted into internal energy. Viscous dissipation effect usually is appreciated on convection with large decelerations from high rotating speeds, high-velocity flow and also in highly viscous flow with moderate velocity [25]. The study of the viscous dissipation effect gained the attention of many researchers recently by Ashraf et al., [26], Zokri et al., [27], Mohamed et al., [28] and Sharada and Shankar [29]. To the best of our knowledge, the present problem is never been considered before, so the results obtained in this study are new.

\section{Mathematical Formulations}

It is assumed a steady two-dimensional boundary layer flow over a vertical moving plate embedded in a nanofluid of ambient temperature, $T_{\infty}$ as shown in Figure 1 . Let $T$ as the temperature inside the boundary layer, $T_{w}$ is the wall temperature, $U_{\infty}$ is the free stream velocity and $u_{w}(x)=\varepsilon U_{\infty}$ is the plate velocity where $\varepsilon$ is the plate velocity parameter. Furthermore, $C_{\infty}$ and $C_{w}$ is the ambient 
and surface nanoparticles volume fraction $C$. The governing boundary layer equations that can be formed are:

$\frac{\partial u}{\partial x}+\frac{\partial v}{\partial y}=0$

$u \frac{\partial u}{\partial x}+v \frac{\partial u}{\partial y}=v \frac{\partial^{2} u}{\partial y^{2}}+g \beta\left(T-T_{\infty}\right)+g \beta_{c}\left(C-C_{\infty}\right)$,

$u \frac{\partial T}{\partial x}+v \frac{\partial T}{\partial y}=\frac{k}{\rho C_{p}} \frac{\partial^{2} T}{\partial y^{2}}+\tau\left[D_{B} \frac{\partial C}{\partial y} \frac{\partial T}{\partial y}+\frac{D_{T}}{T_{\infty}}\left(\frac{\partial T}{\partial y}\right)^{2}\right]+\frac{\mu}{\rho C_{p}}\left(\frac{\partial u}{\partial y}\right)^{2}$

$u \frac{\partial C}{\partial x}+v \frac{\partial C}{\partial y}=D_{B} \frac{\partial^{2} C}{\partial y^{2}}+\frac{D_{T}}{T_{\infty}} \frac{\partial^{2} T}{\partial y^{2}}$

subjected to the boundary conditions

$u=u_{w}(x)=\varepsilon U_{\infty}, v=0, T=T_{w}, C=C_{w}$ at $y=0$,

$u=U_{\infty}, T \rightarrow T_{\infty}, C \rightarrow C_{\infty}$ as $y \rightarrow \infty$,
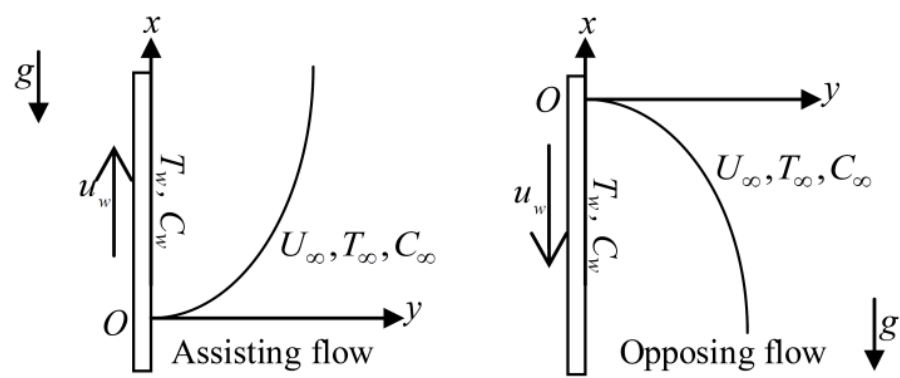

Fig. 1. Physical model and the coordinate system

Eq. (3) is a differential form of Fourier's law of heat conduction which states that rate of heat transfer through a material is proportional to the negative gradient in the temperature per area. From Eq. (1)-(3), $u$ and $v$ are the velocity components along the $x$ and $y$-directions, respectively. $\mu$ is the dynamic viscosity, $v$ is the kinematic viscosity, $\beta$ and $\beta_{c}$ are the thermal and concentration expansion coefficient, respectively. $\rho$ is the fluid density, $k$ is the thermal conductivity and $C_{p}$ is the specific heat capacity at constant pressure. Next, $D_{B}$ is the Brownian diffusion coefficient, $D_{T}$ is the thermophoresis diffusion coefficient, $\tau$ is the ratio of the effective heat capacity of the nanoparticles material and the heat capacity of the ordinary fluid.

The similarity transformation for Eq. (1)-(4) subjected to the boundary conditions (5) can be written as follows [30]:

$\eta=\left(\frac{U_{\infty}}{2 v x}\right)^{1 / 2} y, \psi=\left(2 U_{\infty} v x\right)^{1 / 2} f(\eta), \quad \theta(\eta)=\frac{T-T_{\infty}}{T_{w}-T_{\infty}}, \phi(\eta)=\frac{C-C_{\infty}}{C_{w}-C_{\infty}}$ 
where $\phi$ and $\theta$ are the non-dimensional nanoparticles volume fraction and temperature of the fluid, respectively. $\psi$ is the stream function defined as $u=\frac{\partial \psi}{\partial y}$ and $v=-\frac{\partial \psi}{\partial x}$ which identically satisfy Eq. (1). Then, $u$ and $v$ can be derived as

$u=U_{\infty} f^{\prime}(\eta), v=-\left(\frac{U_{\infty} v}{2 x}\right)^{1 / 2} f(\eta)+\frac{U_{\infty} y}{2 x} f^{\prime}(\eta)$,

By substituting the Eq. (6) and Eq. (7) into Eq. (2)-(4), then we have

$f^{\prime \prime \prime}+f f^{\prime \prime}+2 \lambda \theta+2 \omega \phi=0$

$\frac{1}{\operatorname{Pr}} \theta^{\prime \prime}+f \theta^{\prime}+N_{b} \theta^{\prime} \phi^{\prime}+N_{t} \theta^{\prime 2}+E c f^{\prime \prime 2}=0$,

$\phi^{\prime \prime}+\frac{N_{t}}{N_{b}} \theta^{\prime \prime}+$ Lef $\phi^{\prime}=0$

where $\operatorname{Pr}=\frac{v \rho C_{p}}{k}$ is the Prandtl number, $\lambda=\frac{G r_{x}}{\operatorname{Re}_{x}^{2}}$ is the mixed convection parameter and $\omega=\frac{G r_{c}}{\operatorname{Re}_{x}^{2}}$ is the concentration mixed convection parameter with $G r_{x}=\frac{g \beta\left(T_{w}-T_{\infty}\right) x^{3}}{v^{2}}$ is the Grashof number, $G r_{c}=\frac{g \beta_{c}\left(C_{w}-C_{\infty}\right) x^{3}}{v^{2}}$ is the mass transfer Grashof number and $\operatorname{Re}_{x}=\frac{U_{\infty} x}{v}$ is the Reynolds number. $N_{b}=\frac{\tau D_{B}\left(C_{w}-C_{\infty}\right)}{v}$ is the Brownian motion parameter, $N_{t}=\frac{\tau D_{T}\left(T_{w}-T_{\infty}\right)}{T_{\infty} v}$ is the thermophoresis parameters, $E c=\frac{\left(U_{\infty}\right)^{2}}{C_{p}\left(T_{w}-T_{\infty}\right)}$ is an Eckert number and $L e=\frac{v}{D_{B}}$ is the Lewis number. In order that the similarity solution for Eq. (8)-(10) exist, it is assumed [31]:

$\beta=m x^{-1}$ and $\beta_{c}=n x^{-1}$

where $m$ and $n$ are constants. Note that the assumption in Eq. (11) is necessary for the Eq. (8) to be independent of $x$. The boundary conditions (5) become

$f(0)=0, f^{\prime}(0)=\varepsilon, \theta(0)=1, \phi(0)=1$,

$f^{\prime}(\eta) \rightarrow 1, \theta(\eta) \rightarrow 0, \phi(\eta) \rightarrow 0$, as $y \rightarrow \infty$.

Note that $\varepsilon>0$ and $\varepsilon<0$ corresponds to a downstream and upstream movement of the plate from the origin, respectively. When $\lambda=N_{b}=N_{t}=L e=E c=0$, then Eq. (8) and Eq. (9) becomes

$f^{\prime \prime \prime}+f f^{\prime \prime}=0$ 


$$
\frac{1}{\operatorname{Pr}} \theta^{\prime \prime}+f \theta^{\prime}=0
$$

The above equations can be solve analytically with considering the boundary conditions (12) by taking the exact solution as

$$
f(\eta)=\varepsilon \eta-\frac{\eta^{3}(\varepsilon-1)}{3 \eta_{\infty}^{2}}
$$

Then the solution of $-\theta^{\prime}(0)$ is compute analytically as

$$
-\theta^{\prime}(0)=\frac{1}{\int_{0}^{\infty} e^{-\operatorname{Pr} \int_{0}^{\infty} f(\eta) d \eta} d \eta}
$$

The physical quantities of interest are the skin friction coefficient $C_{f}$, the local Nusselt number $N u_{x}$ and Sherwood number $S h_{x}$ which are given by

$$
C_{f}=\frac{\tau_{w}}{\rho u_{e}^{2}}, N u_{x}=\frac{x q_{w}}{k\left(T_{w}-T_{\infty}\right)}, S h_{x}=\frac{x j_{w}}{D_{B}\left(C_{w}-C_{\infty}\right)}
$$

The surface shear stress $\tau_{w}$, the surface heat flux $q_{w}$ and the surface mass flux $j_{w}$ are given by

$$
\tau_{w}=\mu\left(\frac{\partial u}{\partial y}\right)_{y=0}, q_{w}=-k\left(\frac{\partial T}{\partial y}\right)_{y=0}, j_{w}=-D_{B}\left(\frac{\partial C}{\partial y}\right)_{y=0},
$$

with $\mu=\rho v$ and $k$ being the dynamic viscosity and the thermal conductivity, respectively. Using the similarity variables in (6) gives

$C_{f}\left(2 \operatorname{Re}_{x}\right)^{1 / 2}=f^{\prime \prime}(0), \quad N u_{x}\left(\operatorname{Re}_{x} / 2\right)^{-1 / 2}=-\theta^{\prime}(0), \quad S h_{x}\left(\operatorname{Re}_{x} / 2\right)^{-1 / 2}=-\phi^{\prime}(0)$

\section{Results and Discussion}

The Matlab software is employed to run the Keller-box algorithm in order to solve the Eq. (8)-(10) numerically. Pertinent parameters namely as the Prandtl number $\mathrm{Pr}$, the mixed convection parameter $\lambda$, the concentration mixed convection parameter $\omega$, the plate velocity parameter $\varepsilon$, the Brownian motion parameter $N_{b}$, the thermophoresis parameter $N_{t}$, the Eckert number $E c$, and Lewis number $L e$ are considered. The step size $\Delta \eta=0.02$ and boundary layer thickness from 4 to 12 is used to ensure the existence of dual solution especially case related to moving and stretching parameters. As expected, the dual solution is obtained for various values of moving parameters. 


\section{Table 1}

Comparison values of $-\theta^{\prime}(0) / \sqrt{2}$ with previous published results for various values of $\operatorname{Pr}$ when

\begin{tabular}{lll}
\multicolumn{3}{l}{$\varepsilon=\lambda=N_{b}=N_{t}=E c=L e=0}$. \\
\hline $\operatorname{Pr}$ & Roşca and Pop [32] & Present \\
\hline 0.7 & 0.29268 & 0.292680 \\
0.8 & 0.30691 & 0.306917 \\
1 & 0.33205 & 0.332057 \\
5 & 057668 & 0.576689 \\
10 & 0.72814 & 0.728141 \\
\hline
\end{tabular}

\section{Table 2}

Comparison values of $-\theta^{\prime}(0)$ with exact solution for various values of $\operatorname{Pr}$ when $\lambda=N_{b}=N_{t}=E c$

\begin{tabular}{lll}
\multicolumn{3}{c}{$L e=0$ and $\varepsilon=1$} \\
\hline $\operatorname{Pr}$ & Exact solution & Keller-box method \\
\hline 0.1 & 0.25231 & 0.25231 \\
0.7 & 0.66756 & 0.66756 \\
1 & 0.79788 & 0.79788 \\
7 & 2.11100 & 2.11100 \\
10 & 2.52313 & 2.52313 \\
\hline
\end{tabular}

In order to validate the efficiency of the Keller-box method, comparisons have been made. Tables 1 and 2 show the comparison values of $-\theta^{\prime}(0) / \sqrt{2}$ with previous results in Roşca and Pop [32] and the exact solution for $-\theta^{\prime}(0)$ from Eq. (13) and Eq. (14) with respect to various values of $\operatorname{Pr}$, respectively. It has been found that both tables provided a very good agreement. Hence, it is confident that the results presented in this study are accurate.

Next, Table 3 presents the values of the reduced Nusselt number $N u_{x}\left(\operatorname{Re}_{x} / 2\right)^{-1 / 2}$ and the reduced Sherwood number $\operatorname{Sh}_{x}\left(\operatorname{Re}_{x} / 2\right)^{-1 / 2}$ for various values of $N_{b}$ and $N_{t}$. From this table, it is conclude that the increase of both parameters $N_{b}$ and $N_{t}$ results to a decrease of $N u_{x}\left(\operatorname{Re}_{x} / 2\right)^{-1 / 2}$ while $S h_{x}\left(\operatorname{Re}_{x} / 2\right)^{-1 / 2}$ increases with the increase of $N_{t}$. Physically, it is suggested that the small values of $N_{b}$ and $N_{t}$ enhance convective heat transfer capabilities while the large values of $N_{b}$ and $N_{t}$ enhance the convective mass transfer capabilities. 


\begin{tabular}{|c|c|c|c|}
\hline \multicolumn{4}{|c|}{$\begin{array}{l}\text { Values of } N u_{x}\left(\operatorname{Re}_{x} / 2\right)^{-1 / 2} \text { and } S h_{x}\left(\operatorname{Re}_{x} / 2\right)^{-1 / 2} \text { for } \\
\text { various values of } N_{b} \text { and } N_{t} \text { when } E c=0.1 \text {, } \\
\operatorname{Pr}=7, L e=10 \text { and } \lambda=\varepsilon=0.5\end{array}$} \\
\hline$N_{b}$ & $N_{t}$ & $N u_{x}\left(\operatorname{Re}_{x} / 2\right)^{-1 / 2}$ & $S h_{x}\left(\operatorname{Re}_{x} / 2\right)^{-1 / 2}$ \\
\hline 0.1 & 0.1 & 0.7847 & 1.9846 \\
\hline 0.2 & 0.1 & 0.4767 & 2.1092 \\
\hline 0.3 & 0.1 & 0.2711 & 2.1252 \\
\hline 0.4 & 0.1 & 0.1406 & 2.1201 \\
\hline 0.5 & 0.1 & 0.0616 & 2.1106 \\
\hline 0.1 & 0.2 & 0.5917 & 2.2458 \\
\hline 0.1 & 0.3 & 0.4486 & 2.6287 \\
\hline 0.1 & 0.4 & 0.3416 & 3.0562 \\
\hline 0.1 & 0.5 & 0.2606 & 3.4864 \\
\hline
\end{tabular}

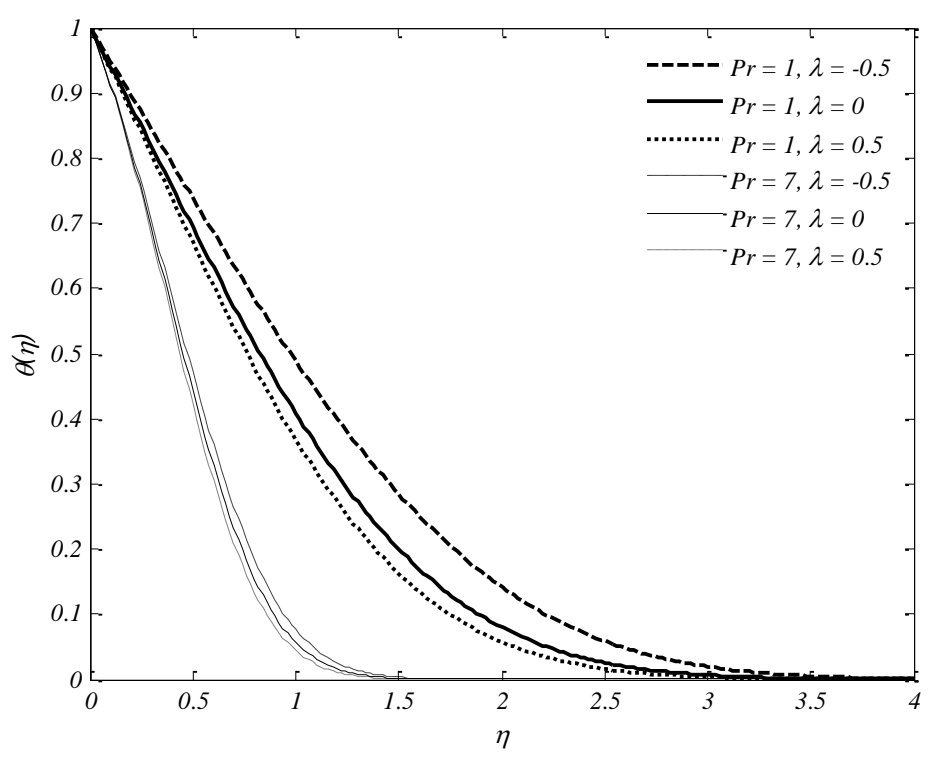

Fig. 2. Effects of $\lambda$ and $\operatorname{Pr}$ on $\theta(\eta)$ when $L e=10, N_{b}=N_{t}=E c=0.1$ and $\varepsilon=\omega=0.5$

Figures 2 to 6 illustrate the temperature profiles $\theta(\eta)$, velocity profiles $f^{\prime}(\eta)$ and concentration profiles $\phi(\eta)$ for parameters discussed. From Figure 2, it is found that as Pr increases, the thermal boundary layer thickness decreases. It is not surprisingly due to a decreasing in thermal diffusivity which leads to a reducing in spreading energy ability in the thermal boundary layer. Further, the presence of mixed convection parameter $\lambda$ in assisting flow $(\lambda>0)$ results to a reducing in thermal boundary layer thickness. The situation is contrary to the opposing flow $(\lambda<0)$ where the boundary layer thickness is increased. From Figure 3, the increase of plate velocity parameter $\varepsilon$ which denoted the ratio of the plate velocity over the free stream velocity reduced the thermal boundary layer thickness. Next, it is suggested that the effects of $\omega$ is similar with $\lambda$ in Figure 2.

Figure 4 shows the $f^{\prime}(\eta)$ for various values of $E c$ and $\omega$, respectively. From Figure 4 , the presence of concentration mixed convection parameter as opposing flow plays a role in reducing the boundary 
layer thickness while the opposing flow does oppositely. Further, it is seen that $E$ c gives a small effect on flow where the increase of $E c$ results to a decreasing in a boundary layer thicknesses.

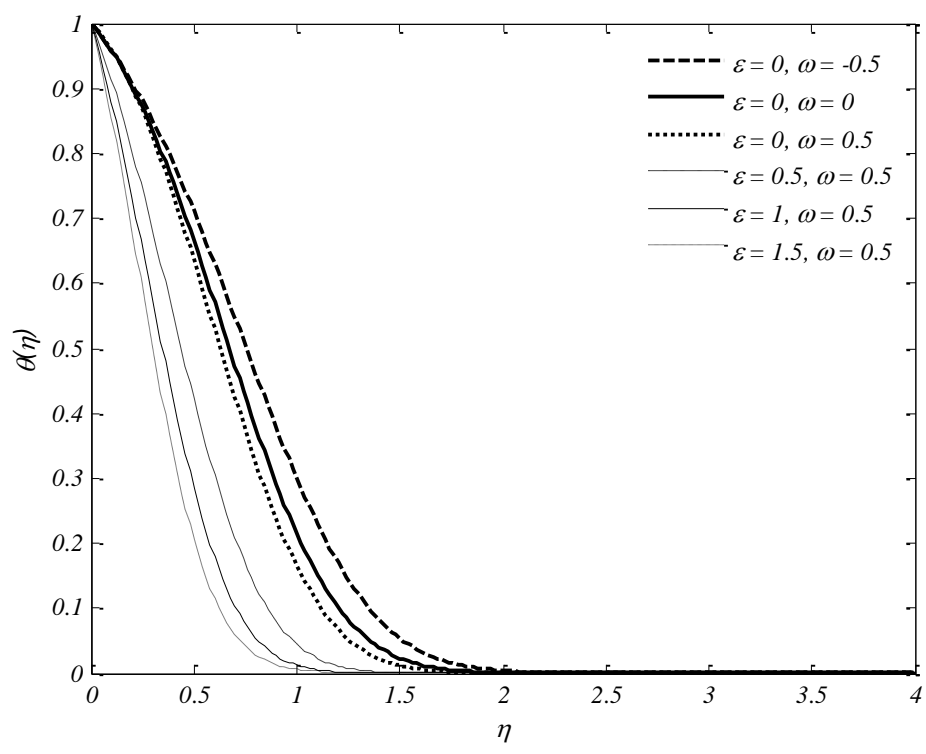

Fig. 3. Effects of $\varepsilon$ and $\omega$ on $\theta(\eta)$ when $\operatorname{Pr}=7, \lambda=0.5, N_{b}=N_{t}=E c=0.1$ and $L e=10$.

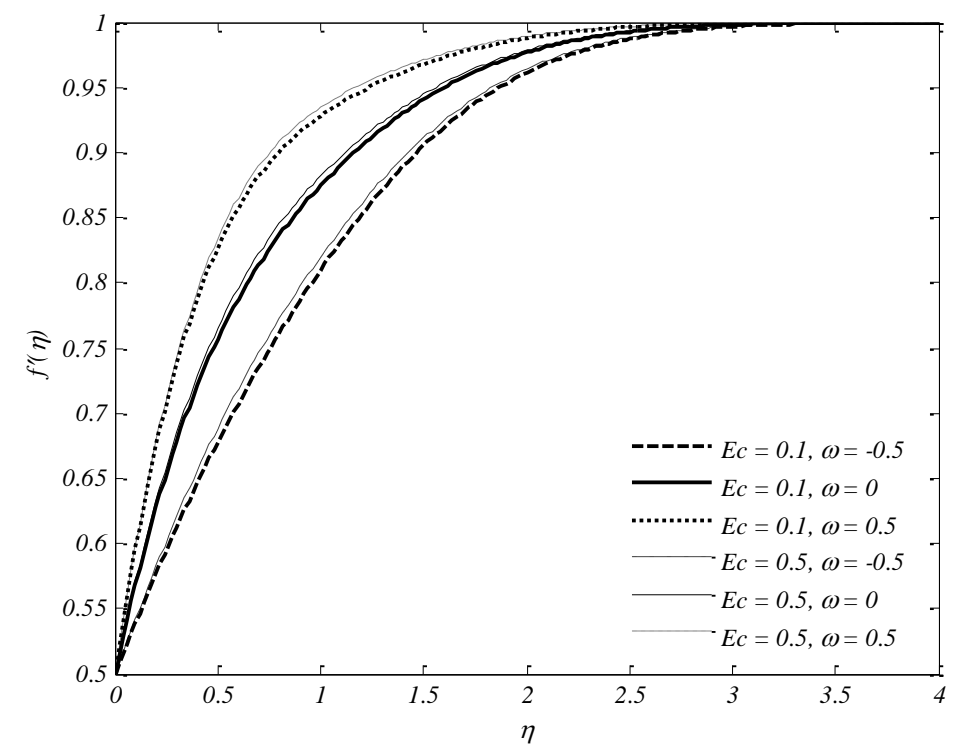

Fig. 4. Effects of $E C$ and $\omega$ on $f^{\prime}(\eta)$ when $\operatorname{Pr}=7, \lambda=\varepsilon=0.5, N_{b}=N_{t}=0.1$ and $L e=10$.

Next, the concentration profiles $\phi(\eta)$ for various values of $N_{b}, \lambda, L e$ and $\omega$ are shown in Figures 5 and 6 , respectively. Similar trend as in Figure 2, the presence of $\lambda$ and $\omega$ as the assisting flow gives a reducing in boundary layer thickness as well as reducing in concentration while opposing flow does the contrary. This may explain as follows; in assisting buoyant flow, as the flow in free stream velocity moves upwards against the gravity acceleration, the nanoparticles in nanofluid will slowly left behind which leads to a reduction of nanoparticles concentration in nanofluid and boundary layer thickness. In considering the $N_{b}$ effects, it is found that as $N_{b}$ increases, the concentration decreases. 
Further, it is suggested that the effect of $\omega$ is negligible with small values of Le. From Figure 6 , it is found that the increase in Le results to the increase in concentration and the thickness of the boundary layer.

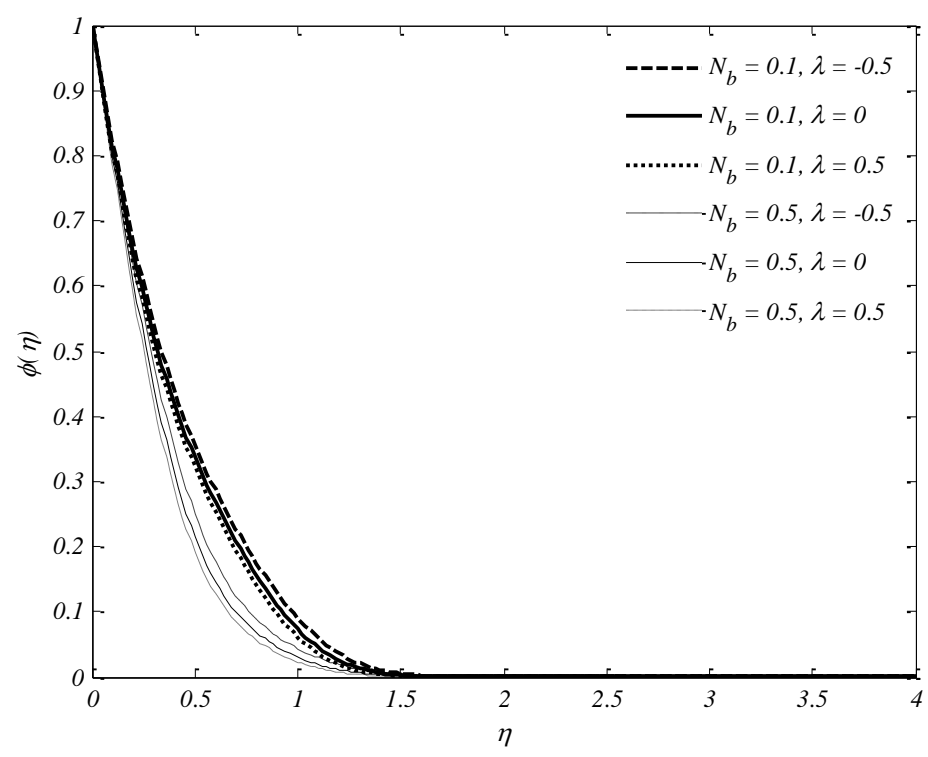

Fig. 5. Effects of $\lambda$ and $N_{b}$ on $\phi(\eta)$ when $\operatorname{Pr}=7, L e=10, N_{t}=E c=0.1$ and $\varepsilon=\omega=0.5$

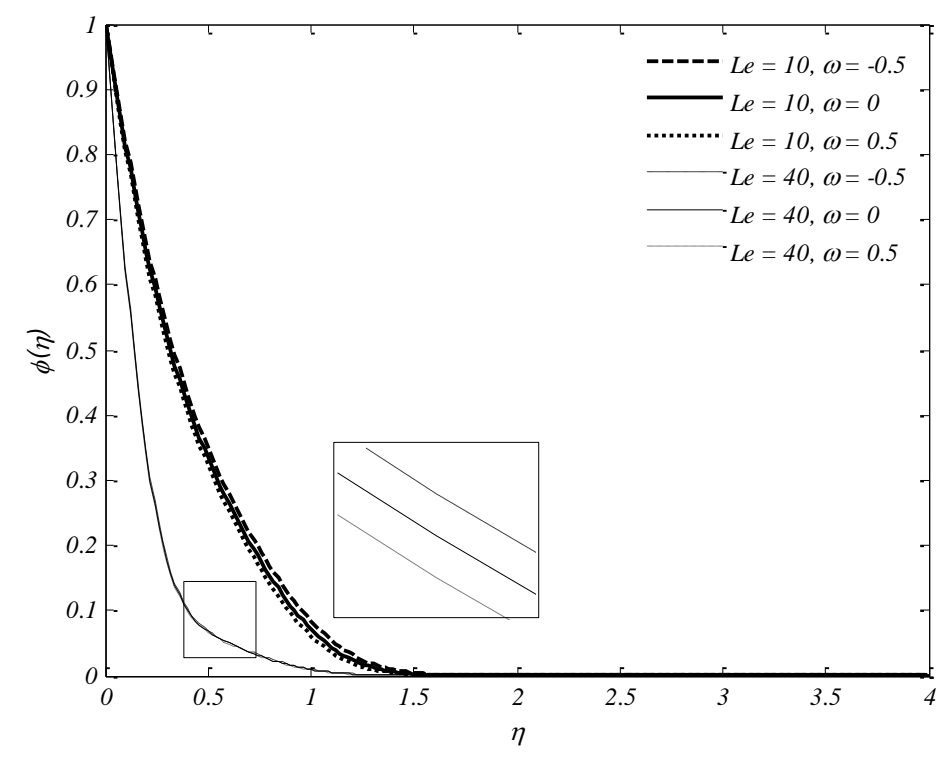

Fig. 6. Effects of Le and $\omega$ on $\phi(\eta)$ when $\lambda=\varepsilon=0.5, N_{b}=N_{t}=0.1$ and $\operatorname{Pr}=7$

In order to investigate the behaviour of Nusselt number, Sherwood number as well the skin friction coefficient, Figures 7 to 15 were plotted. Figure 7 shows the variation of reduced Nusselt number $N u_{x}\left(\operatorname{Re}_{x} / 2\right)^{-1 / 2}$ with $\varepsilon$ for various values of $\lambda$. From the figure, it is suggested that the presence of $\lambda$ in assisting flow has increase the values of $N u_{x}\left(\operatorname{Re}_{x} / 2\right)^{-1 / 2}$ while for opposing flow, the value of $N u_{x}\left(\operatorname{Re}_{x} / 2\right)^{-1 / 2}$ is decreasing. When $\lambda=-0.5$, It is worth mentioning the existence of dual 
solution for $0.18<\varepsilon<0.48$. Further, it is concluded that for $\varepsilon<2$, the increase of $\varepsilon$ has increase the value of $N u_{x}\left(\operatorname{Re}_{x} / 2\right)^{-1 / 2}$ while for $\varepsilon>2$, it is found that the value of $N u_{x}\left(\operatorname{Re}_{x} / 2\right)^{-1 / 2}$ tends to $N u_{x}\left(\operatorname{Re}_{x} / 2\right)^{-1 / 2}=0$, which denoted as pure heat conduction process.

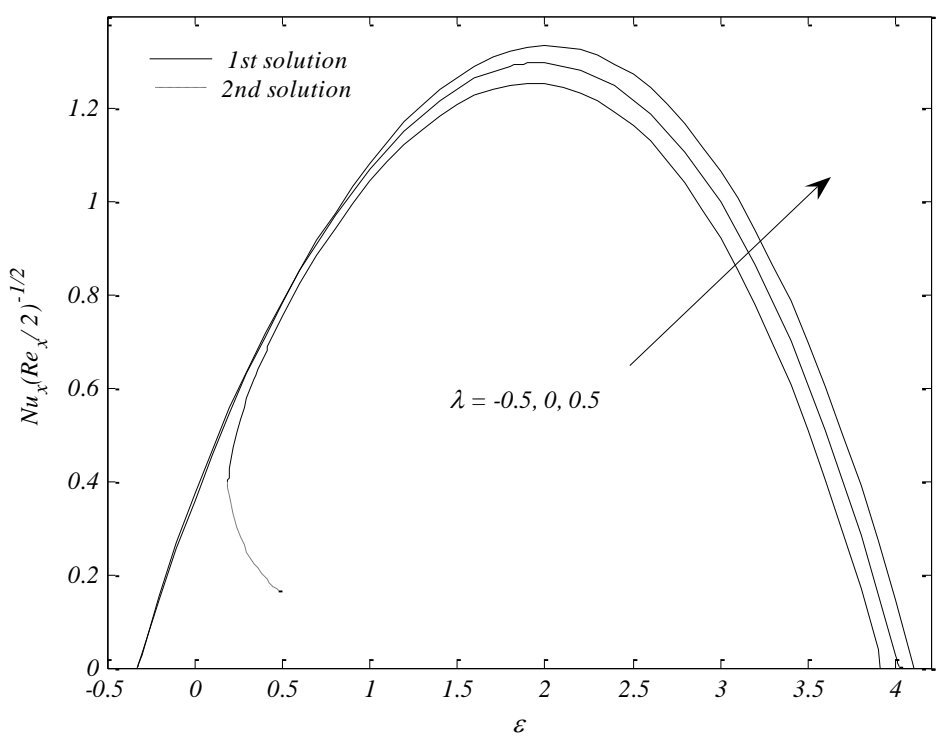

Fig. 7. Variation of $N u_{x}\left(\operatorname{Re}_{x} / 2\right)^{-1 / 2}$ with $\varepsilon$ and $\lambda$ when $\operatorname{Pr}=7, L e=10, \omega=0$ and $N_{b}=N_{t}=E c=0.1$

The variation of $N u_{x}\left(\operatorname{Re}_{x} / 2\right)^{-1 / 2}$ with $\operatorname{Pr}$ for various values of $\omega$ is illustrated in Figure 8. It was found that small values of $\operatorname{Pr}$ such as liquid metals $(\operatorname{Pr} \leq 1)$ produce a very small value of $N u_{x}\left(\operatorname{Re}_{x} / 2\right)^{-1 / 2}$ which implies that no convection which occurs or the heat transfer is in pure conduction situation. It is realistic since liquid metals have high thermal conductivity but low in viscosity. For the fixed value of $\operatorname{Pr}$, the assisting flow of $\omega,(\omega>0)$ increases the values of $N u_{x}\left(\operatorname{Re}_{x} / 2\right)^{-1 / 2}$ while for the opposing flow $(\omega<0)$, the value of $N u_{x}\left(\operatorname{Re}_{x} / 2\right)^{-1 / 2}$ is decreasing.

The variation of $N u_{x}\left(\operatorname{Re}_{x} / 2\right)^{-1 / 2}$ with Le for various values of $\varepsilon$ and $E c$ is shown in Figure 9. It is suggested that the increase of $E c$ has reduced the value of $N u_{x}\left(\operatorname{Re}_{x} / 2\right)^{-1 / 2}$. The effect of $E c$ on $N u_{x}\left(\operatorname{Re}_{x} / 2\right)^{-1 / 2}$ is more pronounced as $\varepsilon$ getting small. Next, it is seen that $N u_{x}\left(\operatorname{Re}_{x} / 2\right)^{-1 / 2}$ is a decreasing function against $L e$. It is due to the increase of thermal diffusivity as $L e$ increases which lead to the pronounced of thermal conductivity effects as well as the conductive heat transfer process and reduced the convective heat transfer rate. 


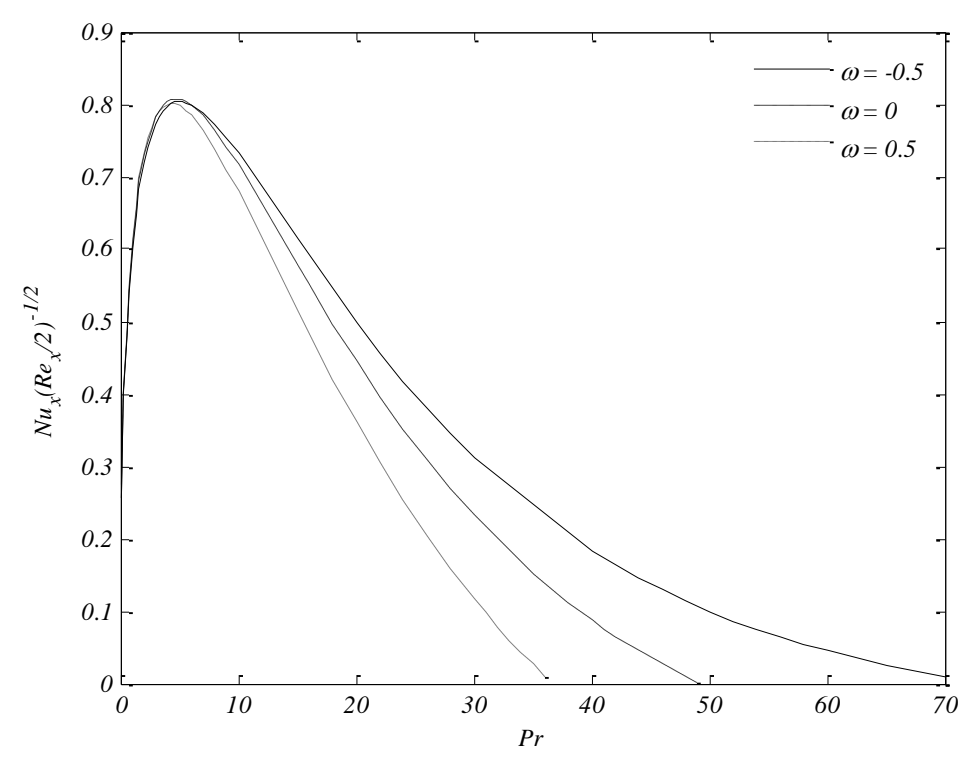

Fig. 8. Variation of $N u_{x}\left(\operatorname{Re}_{x} / 2\right)^{-1 / 2}$ with $\varepsilon$ and $\omega$ when $\operatorname{Pr}=7, L e=10, \lambda=0.5$ and $N_{b}=N_{t}=E c=0.1$

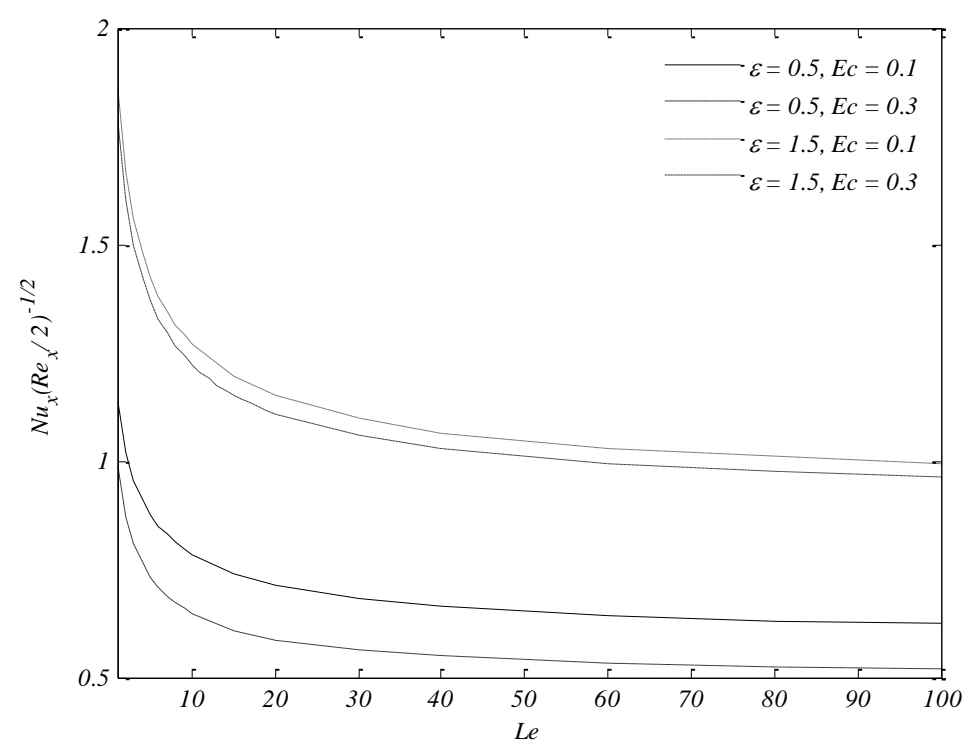

Fig. 9. Variation of $N u_{x}\left(\operatorname{Re}_{x} / 2\right)^{-1 / 2}$ with $L e, \varepsilon$ and $E c$ when $\operatorname{Pr}=7, \lambda=0.5, \omega=0$ and $N_{b}=N_{t}=0.1$

Figure 10 to 12 illustrate the variation of the reduced Sherwood number $S h_{x}\left(\operatorname{Re}_{x} / 2\right)^{-1 / 2}$ with various values of $\lambda, \varepsilon, \omega, \operatorname{Pr}$ and $L e$. From Figure 10, generally it is found that the increase of $\varepsilon$ results to the increase in $S h_{x}\left(\operatorname{Re}_{x} / 2\right)^{-1 / 2}$. When $\lambda=-0.5$, there exist dual solution for $0.18<\varepsilon<0.48$ while no solution is obtained for $\varepsilon<0.18$. In discussing the effects of $\lambda$, for $0<\varepsilon<0.17$, it is observed that for assisting flow, the presence of mixed convection parameter has increased the value of $S h_{x}\left(\operatorname{Re}_{x} / 2\right)^{-1 / 2}$ while in opposing flow, the $S h_{x}\left(\operatorname{Re}_{x} / 2\right)^{-1 / 2}$ decreases. The effects of $\varepsilon$ on $S h_{x}\left(\operatorname{Re}_{x} / 2\right)^{-1 / 2}$ are too small 
at $0.17 \leq \varepsilon \leq 1.9$ while for $\varepsilon>1.9$, it is found that the opposite trends occur where the presence of $\lambda$ in assisting flow has reduced the $S h_{x}\left(\operatorname{Re}_{x} / 2\right)^{-1 / 2}$ while opposing flow does the contrary.

In Figure 11 and 12, it is clear to state that the increase of $\operatorname{Pr}$ and $L e$ enhanced the $S h_{x}\left(\operatorname{Re}_{x} / 2\right)^{-1 / 2}$ values. It is because, when $L e$ increases, the mass diffusivity effects decreases which in turn enhanced the effects of mass transfer rate and lead to the increase of $S h_{x}\left(\operatorname{Re}_{x} / 2\right)^{-1 / 2}$. In considering the $\varepsilon$ effects, it is found that the presence of $\varepsilon$ generally increase the value of $S h_{x}\left(\operatorname{Re}_{x} / 2\right)^{-1 / 2}$. It is worth mentioning that, when velocity parameter is absent $(\varepsilon=0)$, the boundary conditions agree with Blasius flow and when $\varepsilon=1$, the plate and fluid flow are in the same velocity. Further, the presence of assisting flow of $\omega,(\omega>0)$ enhanced the values of $S h_{x}\left(\operatorname{Re}_{x} / 2\right)^{-1 / 2}$ which denoted to the increase in convective mass transfer capability. Meanwhile, for the opposing flow $(\omega<0)$, the values of $\operatorname{Sh}_{x}\left(\operatorname{Re}_{x} / 2\right)^{-1 / 2}$ is decreasing.

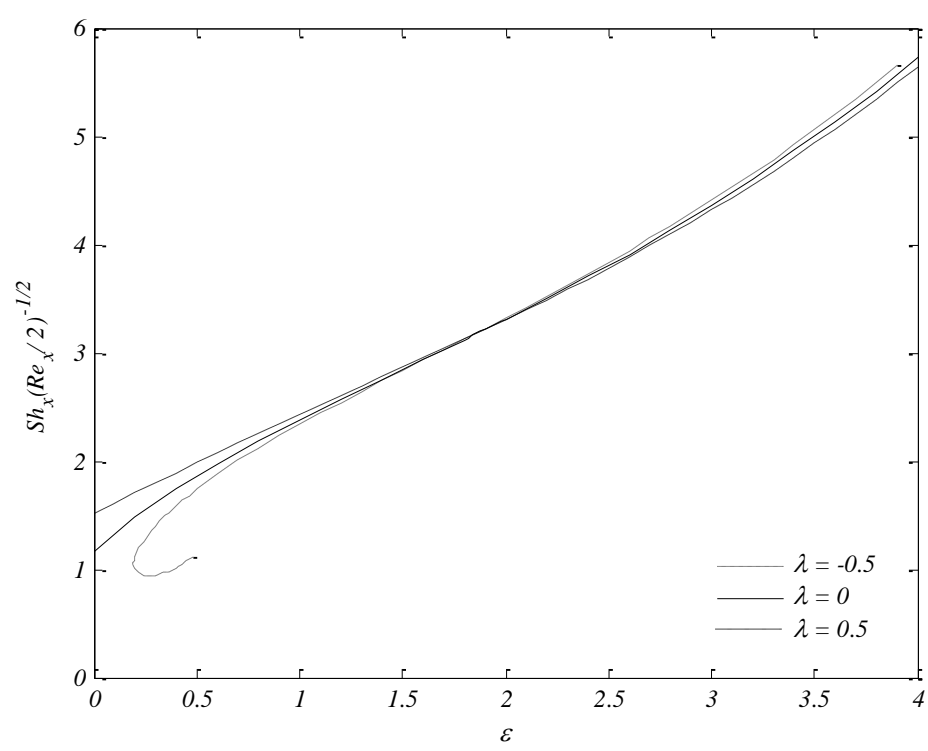

Fig. 10. Variation of $S h_{x}\left(\operatorname{Re}_{x} / 2\right)^{-1 / 2}$ with $\varepsilon$ and $\lambda$ when $\operatorname{Pr}=7, L e=10, \omega=0$ and $N_{b}=N_{t}=E c=0.1$ 


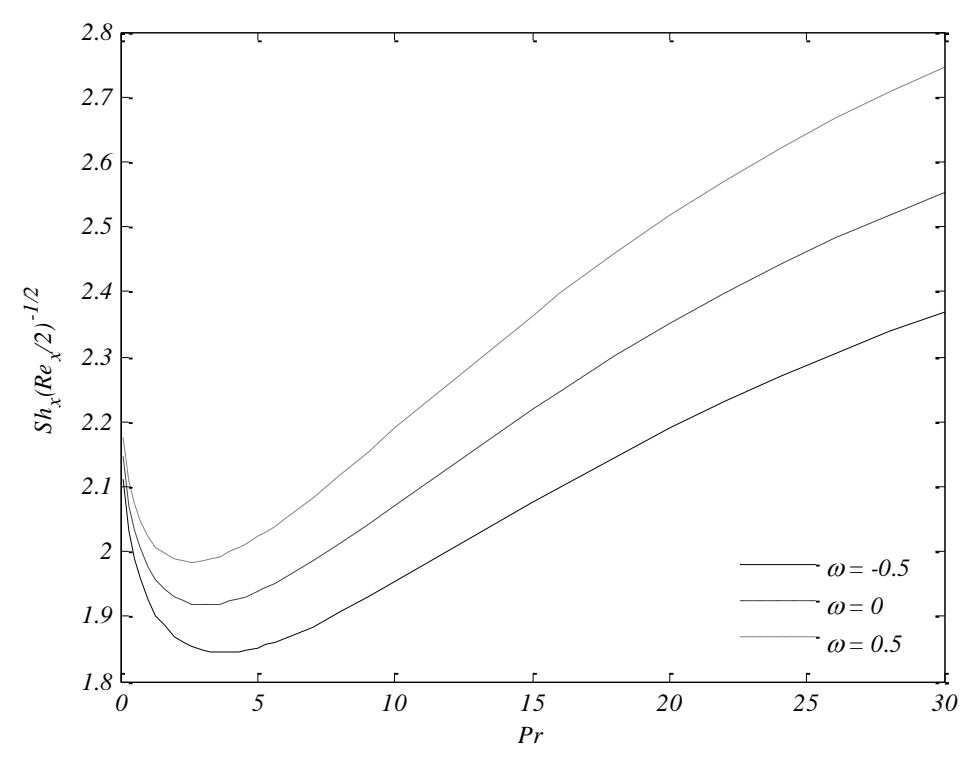

Fig. 11. Variation of $S h_{x}\left(\operatorname{Re}_{x} / 2\right)^{-1 / 2}$ with $\operatorname{Pr}$ and $\omega$ when $\varepsilon=\lambda=0.5, N_{b}=N_{t}=E c=0.1$ and $L e=10$.

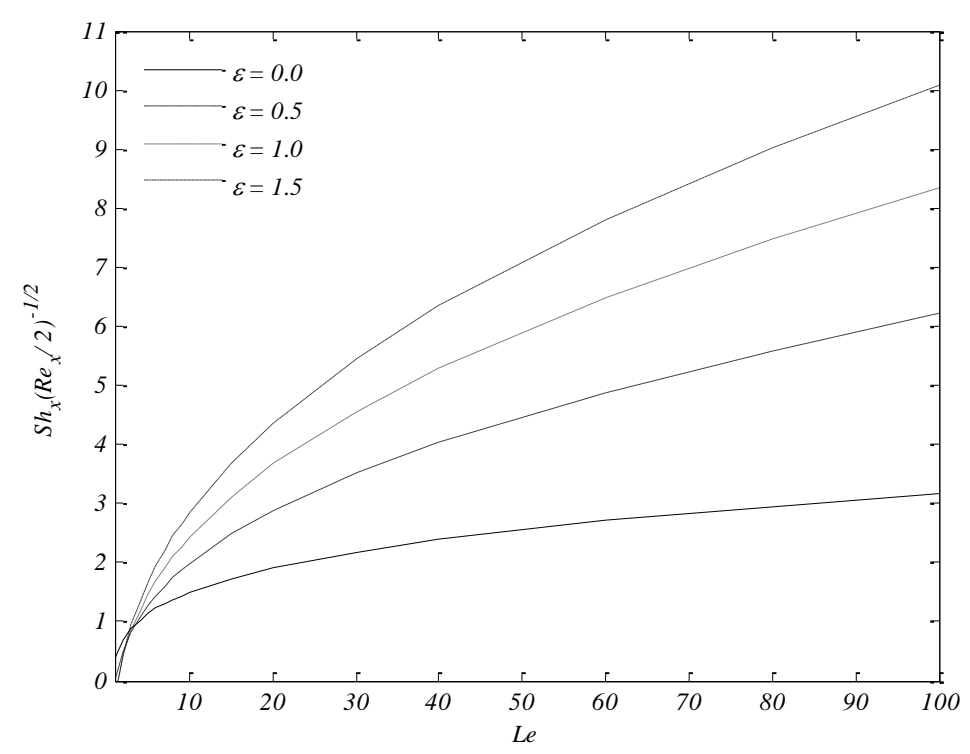

Fig. 12. Variation of $C_{f}\left(2 \operatorname{Re}_{x}\right)^{1 / 2}$ with $L e$ and $\varepsilon$ when $\operatorname{Pr}=7, \lambda=0.5, \omega=0$ and $N_{b}=N_{t}=E c=0.1$

Lastly, Figures 13 to 15 present the variation of the reduced skin friction coefficient $C_{f}\left(2 \operatorname{Re}_{x}\right)^{1 / 2}$ for various values of $\lambda, \varepsilon, \omega, \operatorname{Pr}, E c$ and $L e$, respectively. As in Figures 7 and 10 , dual solutions obtained in Figure 13 for $\lambda=-0.5$. It is shown that the presence of $\lambda$ in assisting flow has increased the value of $C_{f}\left(2 \operatorname{Re}_{x}\right)^{1 / 2}$ while $C_{f}\left(2 \operatorname{Re}_{x}\right)^{1 / 2}$ decreasing in opposing flow. This is because in assisting flow, the kinetic energy produced by $\lambda$ has assisted the boundary layer flow becomes constant close to the plate which in turn shortened the boundary layer thickness and lead to an increase in the velocity gradient or skin friction coefficient. Besides, it is seen that for $\lambda=0, \varepsilon>1$, the values of $C_{f}\left(2 \operatorname{Re}_{x}\right)^{1 / 2}$ is negative due to the plate move faster in the same direction than the stream velocity. Meanwhile, 
as the plate moves slower than the stream velocity fluid, the $C_{f}\left(2 \mathrm{Re}_{x}\right)^{1 / 2}$ is positives. It is noticed that for $\lambda=0, \varepsilon=1$, the $C_{f}\left(2 \operatorname{Re}_{x}\right)^{1 / 2}=0$ due to plate moves equally with stream velocity.

Next, the increase of $\operatorname{Pr}$ in Figure 14 leads to a decrease of $C_{f}\left(2 \operatorname{Re}_{x}\right)^{1 / 2}$. The reduction of $C_{f}\left(2 \operatorname{Re}_{x}\right)^{1 / 2}$ is significant for small values of Pr. For large values of $\mathrm{Pr}$, the changes of these parameter gives a very small and negligible effects on $C_{f}\left(2 \mathrm{Re}_{x}\right)^{1 / 2}$. In considering the effects of $\omega$, it is found that the presence of assisting flow $(\omega>0)$ enhanced the values of $C_{f}\left(2 \operatorname{Re}_{x}\right)^{1 / 2}$ while the opposing flow $(\omega<0)$ reduced the quantity.

In Figure 15, it is clearly shown that the presence of viscous dissipation effects $E c$ has increased the $C_{f}\left(2 \operatorname{Re}_{x}\right)^{1 / 2}$. From a definition of $E c$, the increase of $E c$ is directly proportional to the increase of stream velocity which in turn enhanced the $\varepsilon$ effects on velocity profiles and increase the temperature gradient. In considering the curve individually, it is seen that for $L e<10$, the increase of $L e$ results to the increase drastically in $C_{f}\left(2 \mathrm{Re}_{x}\right)^{1 / 2}$ while for $L e>10$, the value of $C_{f}\left(2 \operatorname{Re}_{x}\right)^{1 / 2}$ decreasing with $L e$.

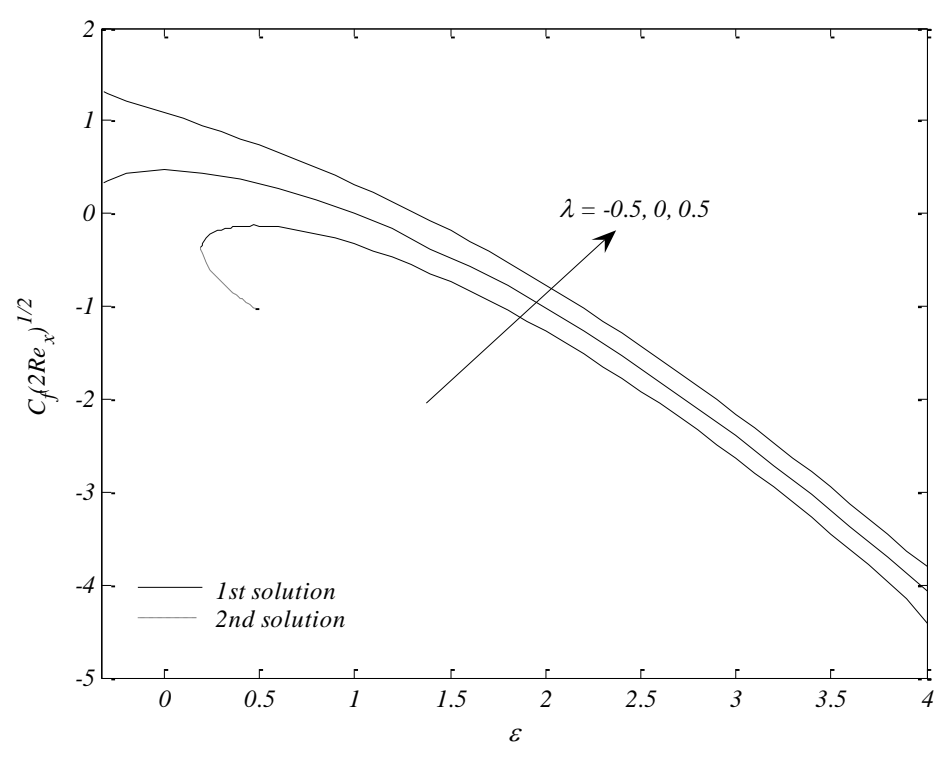

Fig. 13. Variation of $C_{f}\left(2 \operatorname{Re}_{x}\right)^{1 / 2}$ with $\varepsilon$ and $\lambda$ when $\operatorname{Pr}=7, L e=10, \omega=0$ and $N_{b}=N_{t}=E c=0.1$ 


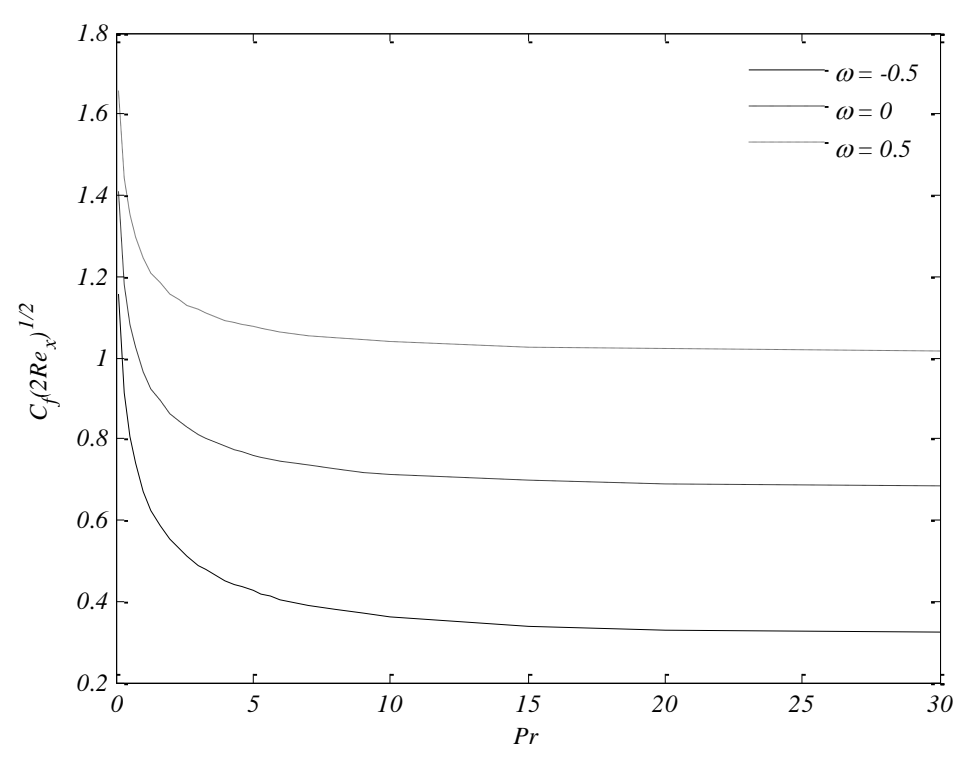

Fig. 14. Variation of $C_{f}\left(2 \operatorname{Re}_{x}\right)^{1 / 2}$ with $\operatorname{Pr}$ and $\omega$ when $\varepsilon=\lambda=0.5, N_{b}=N_{t}=E c=0.1$ and $L e=10$

\section{Conclusions}

The present study has solved the mathematical model of boundary layer flow over a vertical moving plate in a nanofluid with a viscous dissipation effect. The effects of Prandtl number Pr, the mixed convection parameter $\lambda$, the concentration mixed convection parameter $\omega$, the plate velocity parameter $\varepsilon$, the Brownian motion parameter $N_{b}$, the thermophoresis parameter $N_{t}$, the Eckert number $E c$, and Lewis number Le on the reduced Nusselt number, reduced Sherwood numbers and the skin friction coefficient are discussed in details.

As conclusion, the presence of viscous dissipation decreased the Nusselt number while Sherwood number and skin friction increased. Next, the Nusselt number decreases with the increase of $N_{b}$ and $N_{t}$ while the parameter $\varepsilon, N_{t}, \omega$ and Le enhances the Sherwood number which is physically known as convective mass transfer capability.

Next, there exist dual solutions in opposing flow for some values of $\varepsilon$. In considering the $\lambda$ effects, it is found that the increase of $\lambda$ in assisting flow results to the increase in Nusselt number and the skin friction coefficient, these trends are contrary to the opposing flow. 


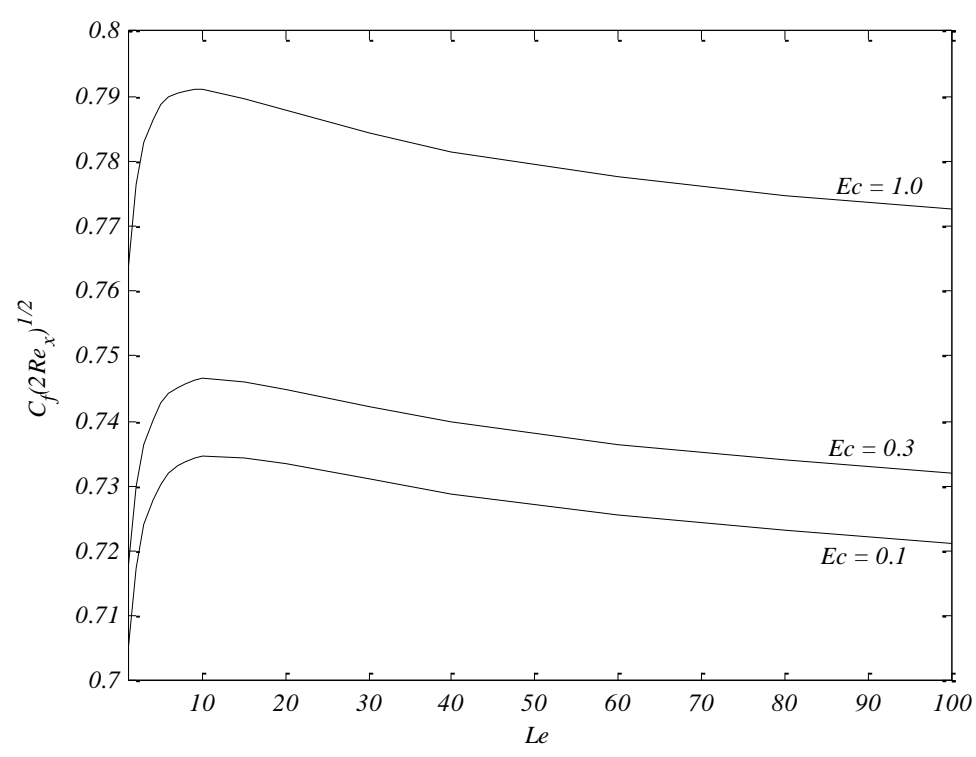

Fig. 15. Variation of $C_{f}\left(2 \operatorname{Re}_{x}\right)^{1 / 2}$ with Le and $E c$ when $\operatorname{Pr}=7, \lambda=\varepsilon=0.5, \omega=0$ and $N_{b}=N_{t}=0.1$

\section{Acknowledgement}

Authors gratefully acknowledge the financial and facilities support from the Malaysia Ministry of Education (FRGS/1/2019/STG06/DHUAM/02/1), DRB-HICOM University of Automotive Malaysia and Universiti Malaysia Pahang.

\section{References}

[1] Sakiadis, Byron C. "Boundary-layer behavior on continuous solid surfaces: I. Boundary-layer equations for twodimensional and axisymmetric flow." American Institute of Chemical Engineers (AIChE) Journal 7, no. 1 (1961): 2628. https://doi.org/10.1002/aic.690070108

[2] Erickson, L. E., L. T. Fan, and V. G. Fox. "Heat and mass transfer on moving continuous flat plate with suction or injection." Industrial \& Engineering Chemistry Fundamentals 5, no. 1 (1966): 19-25. https://doi.org/10.1021/i160017a004

[3] Damseh, Rebhi A., Montasser S. Tahat, and A. C. Benim. "Nonsimilar solutions of magnetohydrodynamic and thermophoresis particle deposition on mixed convection problem in porous media along a vertical surface with variable wall temperature." Progress in Computational Fluid Dynamics, an International Journal 9, no. 1 (2009): 5865. https://doi.org/10.1504/PCFD.2009.022309

[4] Ishak, Anuar, Nor Azizah Yacob, and Norfifah Bachok. "Radiation effects on the thermal boundary layer flow over a moving plate with convective boundary condition." Meccanica 46, no. 4 (2011): 795-801. https://doi.org/10.1007/s11012-010-9338-4

[5] Jahan, Esrat, M. Ferdows, M. A. A. Hamad, and Adrian Postelnicu. "Magneto micro-polar flow considering weak concentration over a vertical porous surface in the presence of viscous dissipation and Ohmic heating: effects of Hall and ion-slip currents." Progress in Computational Fluid Dynamics, an International Journal 12, no. 6 (2012): 415-426. https://doi.org/10.1504/PCFD.2012.049813

[6] Mutlag, A. A., Md Jashim Uddin, and Ahmad Izani Md Ismail. "Scaling transformation for free convection flow of a micropolar fluid along a moving vertical plate in a porous medium with velocity and thermal slip boundary conditions." Sains Malaysiana 43, no. 8 (2014): 1249-1257.

[7] Chamkha, Ali J., S. M. M. EL-Kabeir, and A. M. Rashad. "Unsteady coupled heat and mass transfer by mixed convection flow of a micropolar fluid near the stagnation point on a vertical surface in the presence of radiation and chemical reaction." Progress in Computational Fluid Dynamics 15, no. 3 (2015): 186-196. https://doi.org/10.1504/PCFD.2015.069576 
[8] Jamaludin, Anuar, Roslinda Nazar, and loan Pop. "Ingham problem for mixed convection flow of a nanofluid over a moving vertical plate with suction and injection effects." Sains Malaysiana 47, no. 9 (2018): 2213-2221.

https://doi.org/10.17576/ism-2018-4709-32

[9] Anuar, Nur Syazana, Norfifah Bachok, and loan Pop. "A stability analysis of solutions in boundary layer flow and heat transfer of carbon nanotubes over a moving plate with slip effect." Energies 11, no. 12 (2018): 3243. https://doi.org/10.3390/en11123243

[10] Shamshuddin, M. D., O. Anwar Bég, M. Sunder Ram, and A. Kadir. "Finite element computation of multi-physical micropolar transport phenomena from an inclined moving plate in porous media." Indian Journal of Physics 92 , no. 2 (2018): 215-230. https://doi.org/10.1007/s12648-017-1095-y

[11] Zeeshan, A., N. Shehzad, and R. Ellahi. "Analysis of activation energy in Couette-Poiseuille flow of nanofluid in the presence of chemical reaction and convective boundary conditions." Results in Physics 8 (2018): 502-512. https://doi.org/10.1016/j.rinp.2017.12.024

[12] Hayat, Tasawar, Khursheed Muhammad, Ahmed Alsaedi, and Saleem Asghar. "Numerical study for melting heat transfer and homogeneous-heterogeneous reactions in flow involving carbon nanotubes." Results in physics 8 (2018): 415-421. https://doi.org/10.1016/i.rinp.2017.12.023

[13] Jusoh, Rahimah, Roslinda Nazar, and Ioan Pop. "Magnetohydrodynamic boundary layer flow and heat transfer of nanofluids past a bidirectional exponential permeable stretching/shrinking sheet with viscous dissipation effect." Journal of Heat Transfer 141, no. 1 (2019): 012406. https://doi.org/10.1115/1.4041800

[14] Muhammad, Noor, Sohail Nadeem, and M. T. Mustafa. "Analysis of ferrite nanoparticles in the flow of ferromagnetic nanofluid." PloS One 13, no. 1 (2018): e0188460. https://doi.org/10.1371/journal.pone.0188460

[15] Muhammad, Noor, S. Nadeem, and Alibek Issakhov. "Finite volume method for mixed convection flow of Agethylene glycol nanofluid flow in a cavity having thin central heater." Physica A: Statistical Mechanics and its Applications 537 (2020): 122738. https://doi.org/10.1016/i.physa.2019.122738

[16] Barnoon, Pouya, Davood Toghraie, Reza Balali Dehkordi, and Masoud Afrand. "Two phase natural convection and thermal [] radiation of Non-Newtonian nanofluid in a porous cavity considering inclined cavity and size of inside cylinders." International Communications in Heat and Mass Transfer 108 (2019): 104285.

https://doi.org/10.1016/j.icheatmasstransfer.2019.104285

[17] Toghraie, Davood, Mohammad Mehdi Davood Abdollah, Farzad Pourfattah, Omid Ali Akbari, and Behrooz Ruhani. "Numerical investigation of flow and heat transfer characteristics in smooth, sinusoidal and zigzag-shaped microchannel with and without nanofluid." Journal of Thermal Analysis and Calorimetry 131, no. 2 (2018): 17571766.

https://doi.org/10.1007/s10973-017-6624-6

[18] Ishak, Nazila, Abid Hussanan, Muhammad Khairul Anuar Mohamed, Norhayati Rosli, and Mohd Zuki Salleh. "Heat and mass transfer flow of a viscoelastic nanofluid over a stretching/shrinking sheet with slip condition." In AIP Conference Proceedings, vol. 2059, no. 1, p. 020011. AIP Publishing LLC, 2019. https://doi.org/10.1063/1.5085954

[19] Alkasasbeh, Hamzeh T., Mohammed Z. Swalmeh, Abid Hussanan, and Mustafa Mamat. "Effects of mixed convection on methanol and kerosene oil based micropolar nanofluid containing oxide nanoparticles." CFD Letters 11 , no. 1 (2019): 55-68.

[20] Lee, S., SU-S. Choi, S, and Li, and J. A. Eastman. "Measuring thermal conductivity of fluids containing oxide nanoparticles." Journal of Heat Transfer 121, no. 2 (1999): 280-89. https://doi.org/10.1115/1.2825978

[21] Das, Sarit Kumar, Stephen US Choi, and Hrishikesh E. Patel. "Heat transfer in nanofluids - a review." Heat Transfer Engineering 27, no. 10 (2006): 3-19. https://doi.org/10.1080/01457630600904593

[22] Hu, Z. S., and J. X. Dong. "Study on antiwear and reducing friction additive of nanometer titanium oxide." Wear 216, no. 1 (1998): 92-96. https://doi.org/10.1016/S0043-1648(97)00252-4

[23] Wang, K. V., and O. D. Leon."Applications of Nanofluids: Current and Future." Advances in Mechanical Engineering 2010 (2010): 1-11.

[24] Soundalgekar, V. M. "Viscous dissipation effects on unsteady free convective flow past an infinite, vertical porous plate with constant suction." International Journal of Heat and Mass Transfer 15, no. 6 (1972): 1253-1261. 
https://doi.org/10.1016/0017-9310(72)90189-5

[25] Gebhart, B. "Effects of viscous dissipation in natural convection." Journal of Fluid Mechanics 14, no. 2 (1962): 225232.

https://doi.org/10.1017/S0022112062001196

[26] Ashraf, Muhammad, Almas Fatima, and R. S. R. Gorla. "Periodic momentum and thermal boundary layer mixed convection flow around the surface of a sphere in the presence of viscous dissipation." Canadian Journal of Physics 95, no. 10 (2017): 976-986.

https://doi.org/10.1139/cip-2016-0593

[27] Zokri, Syazwani Mohd, Nur Syamilah Arifin, Muhammad Khairul Anuar Mohamed, Abdul Rahman Mohd Kasim, Nurul Farahain Mohammad, and Mohd Zuki Salleh. "Mathematical model of mixed convection boundary layer flow over a horizontal circular cylinder filled in a Jeffrey fluid with viscous dissipation effect." Sains Malaysiana 47, no. 7 (2018): 1607-1615. https://doi.org/10.17576/jsm-2018-4707-32

[28] Mohamed, Muhammad Khairul Anuar, Norhafizah Md Sarif, Nor Aida Zuraimi Md Noar, Mohd Zuki Salleh, and Anuar Mohd Ishak. "Mixed convection boundary layer flow on a horizontal circular cylinder in a nanofluid with viscous dissipation effect." Malaysian Journal of Fundamental and Applied Sciences 14, no. 1 (2018): 32-39.

[29] Sharada, K., and B. Shankar. "MHD Stagnation Point Flow of a Micropolar Fluid Through a Porous Medium Over an Exponentially Stretching Sheet with Convective Boundary Condition, Viscous Dissipation." Journal of Nanofluids 8 , no. 2 (2019): 394-398.

https://doi.org/10.1166/jon.2019.1596

[30] Bachok, Norfifah, Anuar Ishak, and loan Pop. "Boundary-layer flow of nanofluids over a moving surface in a flowing fluid." International Journal of Thermal Sciences 49, no. 9 (2010): 1663-1668.

https://doi.org/10.1016/i.ijthermalsci.2010.01.026

[31] Makinde, Oluwole D., and P. O. Olanrewaju. "Buoyancy effects on thermal boundary layer over a vertical plate with a convective surface boundary condition." Journal of Fluids Engineering 132, no. 4 (2010): 0445021-24. https://doi.org/10.1115/1.4001386

[32] Roşca, Natalia C., and loan Pop. "Unsteady boundary layer flow of a nanofluid past a moving surface in an external uniform free stream using Buongiorno's model." Computers \& Fluids 95 (2014): 49-55.

https://doi.org/10.1016/j.compfluid.2014.02.011 